DOE/ER/ $13544--5$

DE92 016206

\title{
LASER SPECTROSCOPY AND DYNAMICS OF TRANSIENT SPECIES FORMEL IN PYROLYSIS REACTIONS
}

\author{
Three Year Progress Report \\ June 1, 1989 - May 31, 1992 \\ Dennis J. Clouthier \\ Department of Chemistry \\ University of Kentucky \\ Lexington, KY 40506.0055
}

\section{DISCLAIMER}

This report was prepared as an account of work sponsored by an agency of the United States Government. Neither the United States Government nor any agency thereof, nor any of their employees, makes any warranty, express or implied, or assumes any legal liability or responsibility for the accuracy, completeness, or usefulness of any information, apparatus, product, or process disclosed, or represents that its use would not infringe privatsly owned rights. Reference herein to any specific conmmercial product, process, or service by trade name, trademark, manuiacturer, or otherwise does not necessarily constitute or imply its endorsement, recommendation, or favoring by the United States Government or any agency thereof. The views and opinions of authors expressed herein do not necessarily state or reflect those of the United States Government or any agency thereof.

\section{November 1991}

\section{PREPARED FOR THE U. S. DEPARTMENT OF ENERGY UNDER GRANT NUMBER DE-FG05-86ER13544}

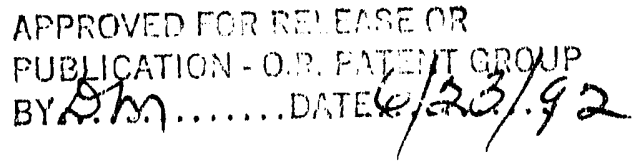


The research proposed under this grant concerns the study of the spectroscopy and excited state dynamics of a number of transient molecules containing either sulfur or oxygen. The identification and study of sulfur species which are analogs of important oxygen-containing combustion intermediates is important to our understanding of reactive intermediates. The oxygen-containing species chosen for study are new systems whose electronic spectra have not previously been identified. The major experimental technique used in this work was pyrolysis jet spectroscopy, a method developed in the last grant period. Since many of the species have not been previously studied by laser techniques, much effort was devoted to determining methods for producing and observing them. We have been very successful in a number of cases and have developed some further experimental techniques. A detailed description of progress in each area is given below.

\section{Sub-Doppler Intracavity Dye Laser Spectroscopy}

During the period of this grant, I spent a year on sabbatical leave in Anthony Merer's lab at the University of British Columbia. During this time, we constructed a sub-Doppler intracavity dye laser spectrometer similar tr that first reported in 1990 by Hill and Field.' By extending the cavity of a Coherent 599 scanning single mode dye laser, and modulating the laser frequency slightly while scanning, we were able to obtain very high resolution (linewidths as low as 10 Mhz) sub-Doppler laser induced fluorescence (LIF) spectra with high sensitivity. Lamb dips are readily apparent in the Doppler broadened line profiles obtained by scanning the laser without frequency modulation and monitoring the broadband LIF signal. The laser was frequency modulated by superimposing a sine wave on the DC ramp voltage used to drive the laser scanning servo mechanism. The component of the fluorescence at twice the sine wave frequency 
was demodulated by a lock-in amplifier to eliminate the Doppler profiles of the lines, giving second-derivative line-shape sub-Doppler spectra. The results of these experiments on specific molecular systems are reported below.

\section{Thioformaldehyde Spectroscopy and Excited State Dynamics}

Since the last grant period, we have completed extensive studies of thioformaldeyde pyrolysis jet spectra and excited state dynamics. In two recently published papers ${ }^{2,3}$ we reported pyrolysis jet spectra of the $S_{1}-S_{0}$ and $T_{1}-S_{0}$ band systems. These rotationally resolved spectra gave rotational constants for $21 \mathrm{~S}_{1}$ levels and $4 \mathrm{~T}_{1}$ levels. The observed rotation-vibration energy levels in each excited state were then fitted to a semirigid invertor model which yielded the potential function for the out-of-plane bending coordinate and the excited state equilibrium geometry. In both states, $\mathrm{H}_{2} \mathrm{CS}$ was found to have a planar equilibrium geometry, in sharp contrast to formaldehyde which is strongly nonplanar in the excited $T_{1}$ and $S_{1}$ states. In the $\tilde{A}$ state, we were able to obtain an unusually complete fit to the parameters of the semirigid invertor model and obtained the novel result that the excited-state bending potential is best described by a single quartic function, without a quadratic term.

We have also published ${ }^{4}$ extensive studies of single rotational level relative quantum yields of fluorescence and fluorescence lifetimes for the $4^{1}$ level of $S_{1}$ thioformaldehyde. It was found that the lifetimes and quantum yields vary with rotational level under collision-free. conditions. About half the levels studied exhibit radiative lifetimes of $\approx 170 \mu \mathrm{s}$, with fluorescence yields of unity. The other levels have longer than radiative lifetimes and some show reduced fluorescence yields. The latter levels can be correlated with sub Doppler perturbations observed by intermodulated fluorescence (IMF), in both ours and earlier work ${ }^{5,6}$, as well as evidence from 
magnetic rotation spectra ${ }^{7}$ and microwave optical double resonance experiments. ${ }^{8.9}$ We proposed a model that qualitatively accounts for the excited state dynamics and predicted the extent of coupling to perturbing ground state levels. At that time, we were unable to directly verify the predictions, since IMF spectroscopy was not sensitive enough to detect the weak "extra lines" buried in the Doppler profiles, arising from direct absorption to the perturbing levels.

Recently, we have been able to obtain a direct view of the sub-Doppler perturbations responsible for the variations in excited state decay behavior in $\mathrm{S}_{1} \mathrm{H}_{2} \mathrm{CS}$. Using the sub-Doppler intracavity dye laser technique, we were able to record very high resolution, very high sensitivity spectra in the $4{ }_{0}^{1}$ band, over a wide range of $\mathrm{J}^{\prime}$ and $\mathrm{K}^{\prime}$, values. In this experiment, $\mathrm{H}_{2} \mathrm{CS}$ was produced by the pyrolysis of trimethylene sulfide vapor at pressures of 5-20 mTorr, flowed into the intracavity spectrometer, and spectra were taken by slow scins over the Doppler profile of each line. A typical example of the results is shown in Figur: 1 for the upper state level $8_{0,8}$ $\left(\mathrm{J}_{\mathrm{KaKc}}\right)$. This is an unperturbed level, as shown by the single line. For the $21_{0,21}$ level, which shows a longer than radiative fluorescence lifetime of $230.8 \mathrm{l}$.s and a fluorescence yield of 0.76 , we obtain the spectrum shown in Figure 2. It clearly shows an extra line and a confirming "center dip" or "crossover resonance" (an artifact of any IMF related scheme). A particularly pronounced example is the $\sigma_{4}$ level, which we predicted from dynamics studies to be perturbed by a number of levels. The $\mathrm{R}_{3}(5)$ transition which populates this level is shown in Figure 3 . The mass of center dips and other lines can be explained as two main lines due to transitions to the two almost degenerate levels $6_{4,3}$ and $6_{4,2}$ and at least 5 "extra lines", with accompanying center dips.

We have surveyed a variety of excited state levels over the range of $\mathrm{K}_{\mathrm{a}}^{\prime}=0$ to 10 , and $\mathrm{J}^{\prime}$ 


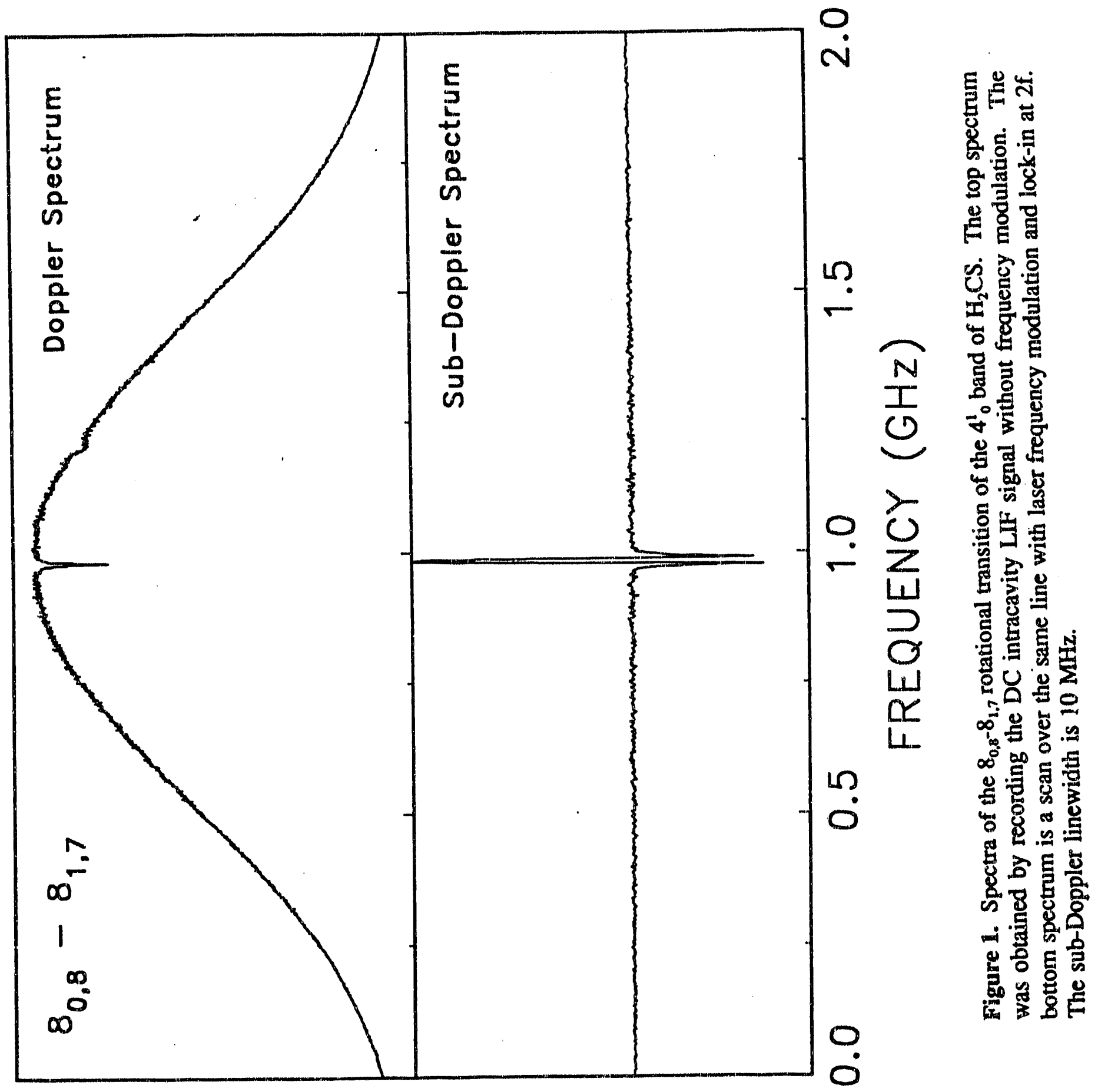




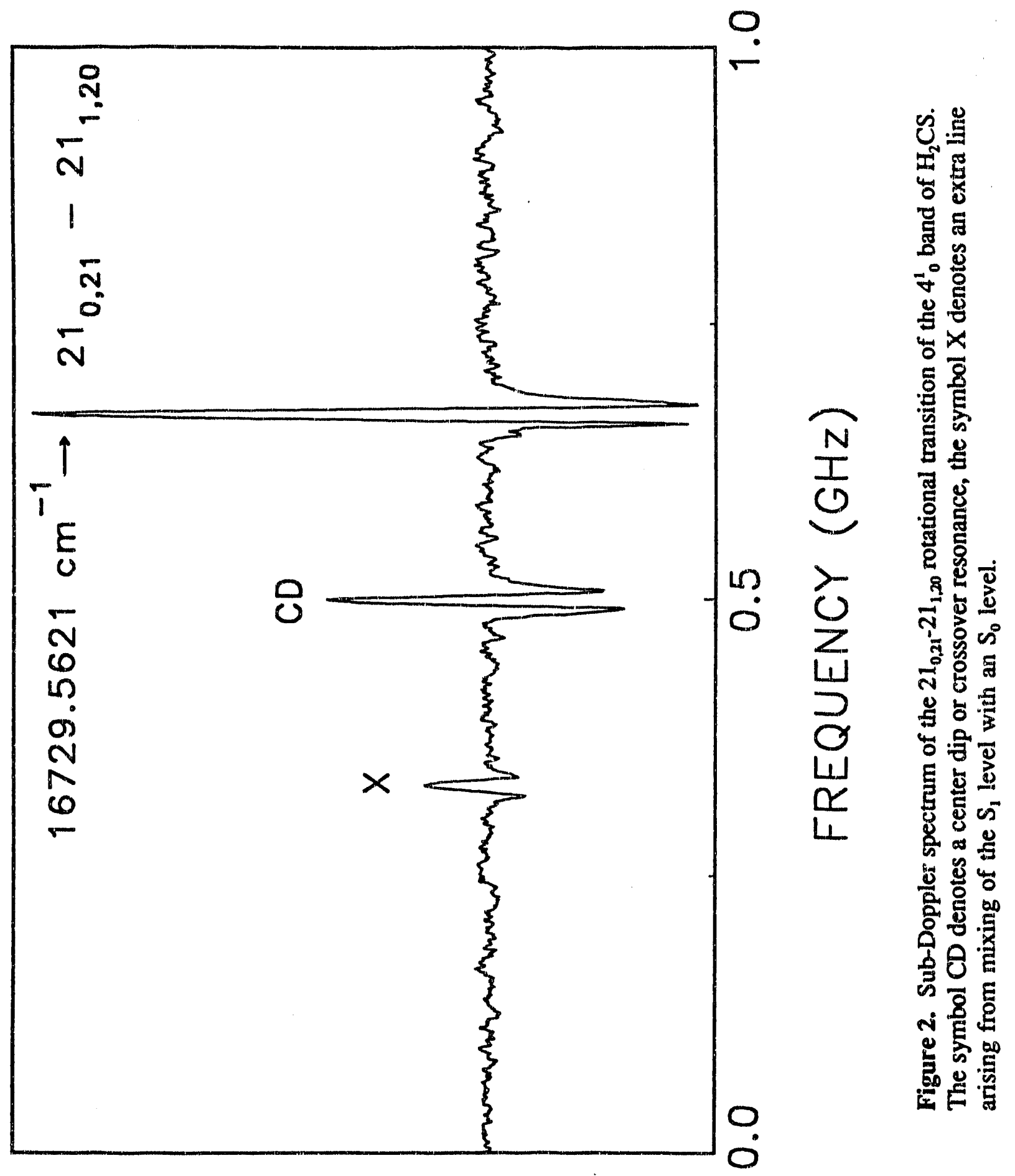




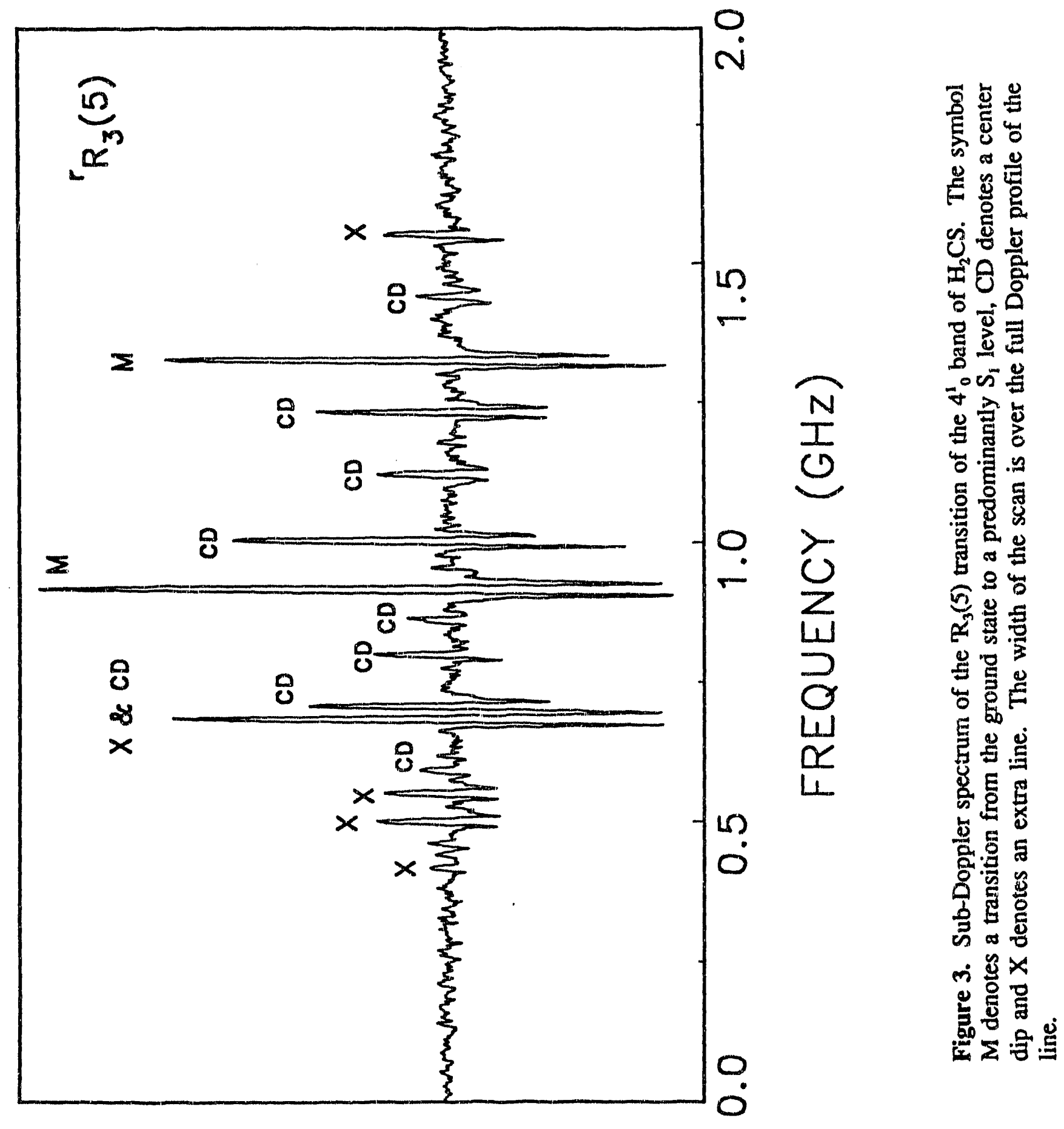


$=0$ to 30 in the $4^{1}$ state. A variety of conclusions can be drawn from these data and a paper on the work has been submitted. ${ }^{10}$ Sub-Doppler perturbations occur in more than $50 \%$ of the levels studied. The levels which show anomalous fluorescence lifetimes and quantum yields correlate directly with observed sub-Doppler perturbations. In fact, this work shows that the lifetime measurements are a very sensitive probe of the coupling between $S_{1}$ and $S_{0}$ levels. Attempts have been made to derive coupling matrix elements from the perturbations, but these have been frustrated by the inadequacy of both the ground and excited state rotational constants. We are able to measure sub-Doppler lines to an absolute accuracy $\pm 15 \mathrm{MHz}$, using the calibration system in the Merer laboratory. By comparing combination differences of ${ }^{\mathrm{P}} \mathrm{P}$ and $\mathrm{R}$ lines, it is readily apparent that the ground state constants ${ }^{7}$, predominantly from microwave measurements of A-type transitions, are not precise enough for the data from this B-type transition. Similarly, the constants available from the analysis of the $4_{0}^{1}$ band at Doppler-limited resolution ${ }^{7}$ do not satisfactorily predict the line frequencies of the unperturbed sub-Doppler transitions. Both of these problems can be solved with sufficient sub-Doppler data, which will then allow us to determine directly the magnitude and sign of each perturbation and the coupling matrix element in suitable cases. Further work along these lines is in progress.

\section{Sub-Doppler Spectroscopy of Metal Oxides}

During my stay in the Merer lab, we were also able to use the intracavity technique to study the hyperfine structure in some electronic transitions of vanadium oxide (VO) and cobalt oxide (CoO). In VO, the $B^{4} \Pi-X^{4} \Sigma(1,0)$ band was studied and values of the principal hyperfine parameters a and $(b+c)$ were deduced from the spectra. The Fermi contact parameter was shown to be sizeable and negative, allowing the electron configuration of the $B^{4} \Pi$ state to be assigned 
as $(3 \mathrm{~d} \delta)^{2}(3 \mathrm{~d} \pi)^{1}$, rather than the alternative $(3 \mathrm{~d} \delta)^{1}(3 \mathrm{~d} \pi)^{1}(4 \mathrm{~s} \sigma)^{1}$. Similar studies of spectra of CoO near $640 \mathrm{~nm}$ show that the ground state has the configuration $\sigma^{2} \pi^{2} \delta^{3}$. A paper on the VO analysis has been submitted for publication. ${ }^{11}$

Extensive wavelength resolved fluorescence studies of $\mathrm{CoO}$, excited by the high power intracavity laser beam, were used to assign previously unassignable regions of the $630-650 \mathrm{~nm}$ absorption system of $\mathrm{CoO}$. Several new bands were found and detailed assignments made. The ground $s$ ate spin-orbit intervals were obtained by pumping perturbed lines and analyzing the emission spectra. These results will be combined with studies in other regions of the spectrum of $\mathrm{CoO}$ to give a detailed map of the complex band systems in this region.

\section{Pyrolysis Jet Spectroscopy of Dichlorocarbene $\left(\mathrm{CCl}_{2}\right)$}

We have now published two papers ${ }^{12,13}$ reporting rotationally resolved pyrolysis jet spectra of dichlorocarbene, a species recently characterized as the correrstone of singlet carbene reactivity. ${ }^{14}$ From high resolution pyrolysis jet spectra, obtained using a single mode $\mathrm{cw}$ ring laser excitation source, we were able to obtain accurate rotational constants for 7 upper and 4 lower state levels of both $\mathrm{C}^{35} \mathrm{Cl}_{2}$ and $\mathrm{C}^{35} \mathrm{Cl}{ }^{37} \mathrm{Cl}$. The electronic transition was determined to be $\tilde{\mathrm{A}}^{1} \mathrm{~B}_{1}-\tilde{\mathrm{X}}^{1} \mathrm{~A}_{1}$, with band origin at $17255.67 \mathrm{~cm}^{-1}$. Upper and lower state geometries were deternined, as were the vibrational frequencies and anharmonicities for the totally symmetric vibrations. We were unable to detect any perturbations in the spectra which might give information on the as yet unobserved lower triplet state.

\section{Pyrolysis Jet Spectroscopy of the Thioethyne Radical (HCCS)}

Our work on this species continues to progress, but we have not been able to complete our analysis, despite considerable effort. Initially, we used 1,2,3-thiadiazole as the precursor for 
producing HCCS/DCCS by pyrolysis. This precursor gave reasonably good spectra for the strong ${ }^{2} \Pi_{3 / 2}{ }^{2} \Pi_{3 / 2}$ bands, which we were able to record at rotationally resolved resolution. These spectra confirm the identity of the transition $\left({ }^{2} \Pi_{i}{ }^{2} \Pi_{i}\right)$ and give the rotational numbering directly, since a strong $\mathrm{Q}$ branch is observed. In order to calibrate these spectra accurately, we invented a new laser calibration method ${ }^{15}$, as discussed later. Unfortunately, all our attempts to record high resolution spectra of bands involving the ${ }^{2} \Pi_{1 / 2}$ component of the lower state have been frustrated by weak LIF signals. In an attempt to overcome the problem, we synthesized, with some difficulty, a new molecule, ethylthioethyne ( $\left.\mathrm{H}-\mathrm{C} \equiv \mathrm{C}-\mathrm{S}-\mathrm{C}_{2} \mathrm{H}_{5}\right)$, which we felt would give HCCS on pyrolysis. Under pyrolysis jet conditions, this compound does give HCCS, and the initial spectra looked promising. However, the compound is not very stable and is difficult to work with, so we have not been able to use it to full advantage.

We have also tried to produce HCCS by photolysis at the exit of a supersonic nozzle. $193 \mathrm{~nm}$ photolysis of 1,2,3-thiadiazole gave weak HCCS signals. Pyrolysis of 1,2,3-thiadiazole to produce thioketene, and then subsequent photolysis did not give any signals. Similarly, photolysis of ethylthioethyne did not give any LIF signals. Experiments are continuing to resolve the difficulties ir, this project.

\section{A New Wavelength Calibration System for Pulsed Lasers in the $500-350 \mathrm{~nm}$ Region}

In the course of our work on HCCS and a number of other species with spectra in the 500-350 nm region, we encountered difficulties in properly wavelength calibrating short (10-30 $\mathrm{cm}^{-1}$ ) etalon scans of our laser. To solve this problem, we invented a new, versatile method of calibration, which has been published in the Review of Scientific Instruments. ${ }^{15}$ It consists of Raman shifting the laser beam which exits the jet apparatus back into the wavelength region 
covered by the high resolution $I_{2}$ atlas. The LIF spectrum of $I_{2}$ is recorded with the Ramanshifted beam and the experimental spectrum is calibrated relative to it. By adding the $\mathrm{H}_{2}$ Raman shift, which can be very accurately calculated as a function of pressure, one can obtain the wavelength of the original laser beam. The method was shown to give results of comparable accuracy to those obtained with pulsed lasers in the conventional $850-500 \mathrm{~nm} \mathrm{I}_{2}$ LIF calibration region.

\section{A Search for the LIF Spectrum of the Ketyl Radical (HCCO)}

Although the LIF spectrum of HCCO was reported in the literature some time ago ${ }^{16}$, it is now known to be that of formaldehyde. ${ }^{17}$ We have attempted several experiments, but have not obtained a spectrum that could be ascribed to HCCO. First, we synthesized trimethylsilylketene $\left(\mathrm{CH}_{3} \mathrm{Si}-\mathrm{CH}=\mathrm{C}=\mathrm{O}\right)$, which was studied by pyrolysis jet and laser flash photolysis techniques. It proved to be a good source of $\mathrm{CH}_{3} \mathrm{O}$ in the pyrolysis jet, but there is no evidence for HCCO bands. Recently, it was reported that $193 \mathrm{~nm}$ photolysis of ketene yields substantial quantities of $\mathrm{HCCO}^{18}$ as detected by diode laser absorption spectroscopy. Encouraged by this observation and recent predictions of the excitation energy ${ }^{19}$, we undertook a search for the spectrum by $193 \mathrm{~nm}$ photolysis of ketene and LIF probing. In scanning from $350-260 \mathrm{~nm}$, we did not observe any signals. We conclude that HCCO is likely nonfluorescent and therefore not detectable by LIF techniques.

\section{High Resolution FTIR Spectroscopy of Formyl Chloride (HCOCl/DCOCI)}

While on sabbatical leave, I had access to a high resolution FTIR spectrometer (Bomem DA3.002) and was able to record several bands of $\mathrm{HCOCl}$ and $\mathrm{DCOCl}$. This molecule is a transient species which decomposes to form $\mathrm{CO}$ and $\mathrm{HCl}$. Although the low resolution IR 
spectrum has been known for a number of years ${ }^{20}$, high resolution studies have not been reported. The molecule is challenging because 5 of the 6 fundamentals are A/B hybrid bands and both the $\mathrm{HCO}^{35} \mathrm{Cl}$ and $\mathrm{HCO}^{37} \mathrm{Cl}$ isotopomers are fairly abundant $(3: 1)$. Thus, the resulting spectra are fairly complex and congested. Despite these impediments, we were able to get well-resolved spectra by using the highest resolution available on the instrument and deconvoluting the spectra to give a resolution of about $0.003 \mathrm{~cm}^{-1}$. We have recorded the $v_{3}, v_{2}, v_{6}$ and $2 v_{6}$ bands of $\mathrm{FiCOCl}$ and the $v_{3}$ and $v_{2}$ bands of DCOCl. A partial analysis of the $v_{3}$ band of $\mathrm{HCOCl}$ has been done, showing that the A-type structure is unperturbed up to $\mathrm{J}^{\prime}=50, \mathrm{~K}_{\mathrm{a}}^{\prime}=13$. The analysis of these bands will be ongoing for some time, as each consists of 2500-3000 resolvable transitions.

\section{Spectroscopy of Formic Acid (HCOOH)}

Formic acid is the simplest carboxylic acid and is the highly oxidized form of a number of simple species important in combustion processes. Surprisingly, there is little information on the electronic spectrum, although the photochemistry has been explored extensively in recent years. ${ }^{21}$ During this grant period, we have published a study of the LIF spectrum of $\mathrm{HCOOH}$ and the various deuterated isotopomers. ${ }^{22}$ The spectra were recorded in a room temperature flow system and firmly established for the first time the location of the $0_{0}^{0}$ band. Our ab initio calculations suggest that the excited state is highly distorted from the planar ground state structure, accounting for the activity in the $\mathrm{H}-\mathrm{C}$ and $\mathrm{O}-\mathrm{H}$ out-of-plane bending coordinates in the spectrum.

Subsequently, we have attempted to do jet spectroscopy on formic acid. This is more difficult, because the fluorescence yield is very low. However, we were able to get low 
resolution jet-cooled spectra and have shown that it is possible to get rotationally resolved spectra. These spectra should be a great help in understanding the complex conformational changes in the $S_{1}$ state of formic acid.

\section{Other Studies}

We have also attempted to observe the spectra of $\mathrm{C}_{2}, \mathrm{~s}, \mathrm{~N}_{2} \mathrm{~S}$ and $\mathrm{C}_{2} \mathrm{O}$ by pyrolysis jet techniques.

Pyrolysis of $\mathrm{C}_{3} \mathrm{OS}$ did not give any LIF signals attributable to $\mathrm{C}_{2} S$, although we previously had obtained a band system in the 700-900 nm region by conventional flash photolysis of $\mathrm{C}_{3} \mathrm{OS}^{23}$

Several precursors krown to produce $\mathrm{N}_{2} \mathrm{~S}$ were synthesized and pyrolyzed, but no LIF spectra were obtained. Subsequent ab initis calculations ${ }^{23}$ suggest that $\mathrm{N}_{2} \mathrm{~S}$ is unbound in the lowest excited states, so that LIF spectroscopy is not suitable for probing the $\mathrm{N}_{2} \mathrm{~S}$ transient molecule.

Pyrolysis jet spectroscopy on fumaryl chloride, a known source of $\mathrm{C}_{3} \mathrm{O}$, has produced weak spectra in the $250-270 \mathrm{~nm}$ region, in agreement with our ab initio predictions for the $\tilde{A}-\tilde{X}$ band system. However, the spectra are presently of insufficient quality to prove that the carrier is $C_{3} \mathrm{O}$. Further experiments using an altemate precursor are planned. 


\section{References}

1. E. J. Hill and R. W. Field, J. Chem. Phys., 93, 1 (1990).

2. J. R. Dunlop, J. Karolczak, D. J. Clouthier and S. C. Ross, J. Phys. Chem., 95, 3045 (1991).

3. J. R. Dunlop, J. Karolczak, D. J. Clout ier and S. C. Ross, J. Phys. Chem., 95, 3063 (1991).

4. J. R. Dunlop and D. J. Clouthier, J. Chem. Phys., 93, 6371 (1990).

5. K. H. Fung and D. A. Ramsay, J. Phys. Chem., 88, 395 (1984).

6. K. H. Fung, J. C. Petersen and D. A. Ramsey, Can. J. Phys., 63, 933 (1985).

7. D. J. Clouthier, D. C. Moule, D. A. Ramsay and F. W. Birss, Can. J. Phys., 60, 1212 (1982).

8. J. C. Petersen and D. A. Ramsay, Chem. Phys. Lett. 124, 406 (1986).

9. J. C. Petersen, D. A. Ramsay and T. Amano, Chem. Phys. Lett., 103, 266 (1984).

10. G. Huang, A. J. Merer and D. J. Clouthier, "A Spectroscopic View of Internal Conversion and Intersystem Crossing in a Small Polyatomic Molecule: Sub-Doppler Intracavity Dye Laser Spectroscopy of Thioformaldehyde", J. Chem. Phys., submitted.

11. G. Huang, A. J. Merer and D. J. Clouthier, "Intracavity Laser Spectroscopy of VO: Hyperfine Parameters and Electron Configuration of the $B^{4} \Pi$ State", J. Mol. Spectrosc., submitted.

12. D. J. Clouthier and J. Karolczak, J. Phys. Chem., 93, 7542 (1989).

13. D. J. Clouthier and J. Karolczak, J. Chem. Phys., 94, 1 (1991).

14. J. E. Chateauneuf, R. P. Johnson and M. M. Kirchhoff, J. A. C. S., 112, 3217 (1990).

15. D. J. Clouthier and J. Karolczak, Rev. Sci. Instrum., 61, 1607 (1990).

16. G. Inoue and M. Suzuki, J. Chem. Phys., 84, 3709 (1986).

17. G. Inoue and M. Suzuki, J. Chem. Phys., 92, 815 (1990).

18. K. G. Unfried, G. P. Glass and R. F. Curl, Chem. Phys. Lett, 177, 33 (1991). 
19. K. Kim and I. Shavitt, "Electronic Structure of HCCO Radical", Paper RG2, 46th International Symposium on Molecular Spectroscopy, June, 1991.

20. R. Wellington Davis and M. C. L. Gerry, J. Mol. Spectrosc., 97, 117 (1983) and references therein.

21. M. Brouard and J. O'Mahony, Chem. Phys. Lett., 149, 45 (1988) and references therein.

22. F. Ioannoni, D. C. Moule and D. J. Clouthier, J. Phys. Chem., 94, 2290 (1990).

23. D. J. Ciouthier, unpublished results. 

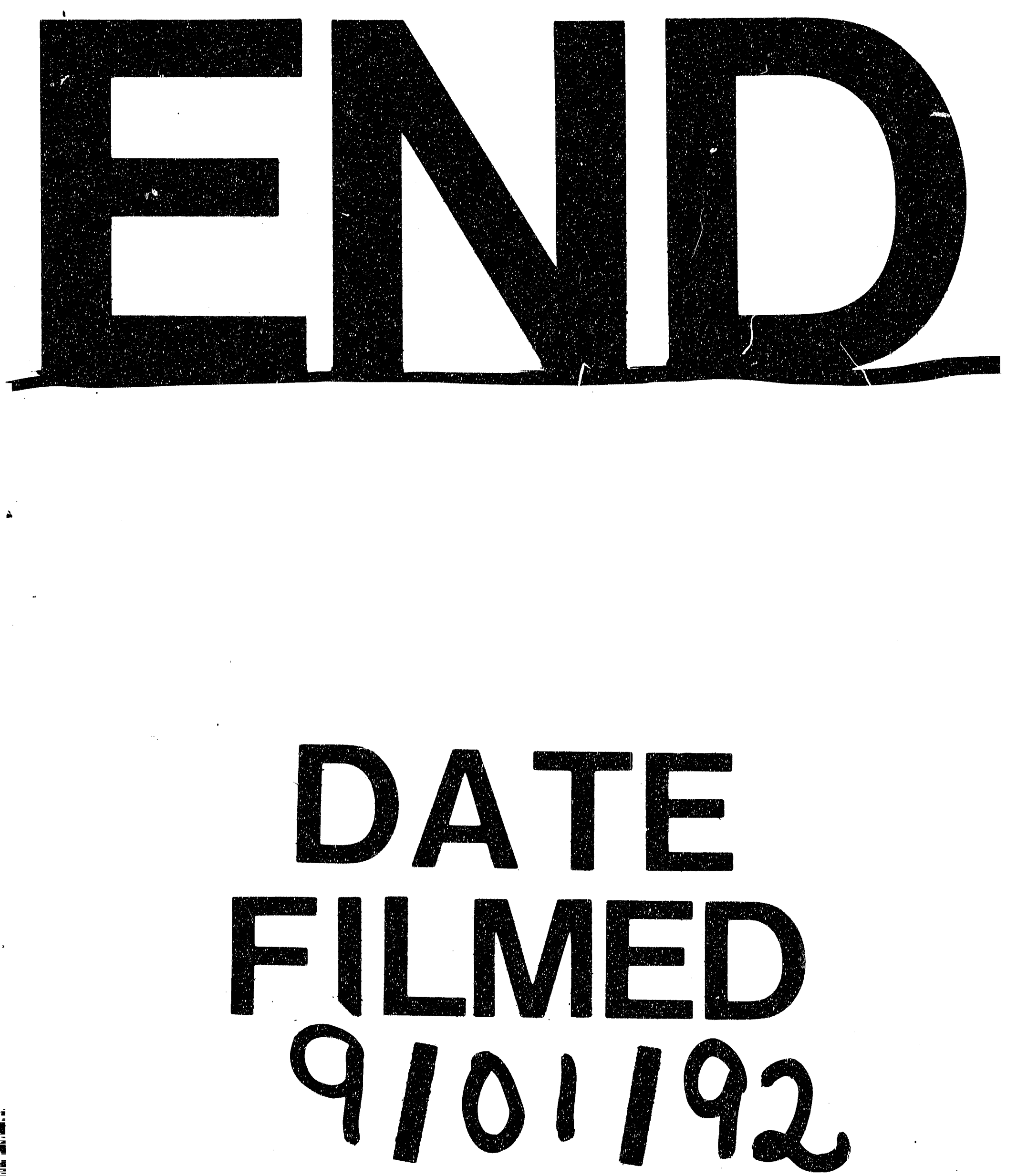


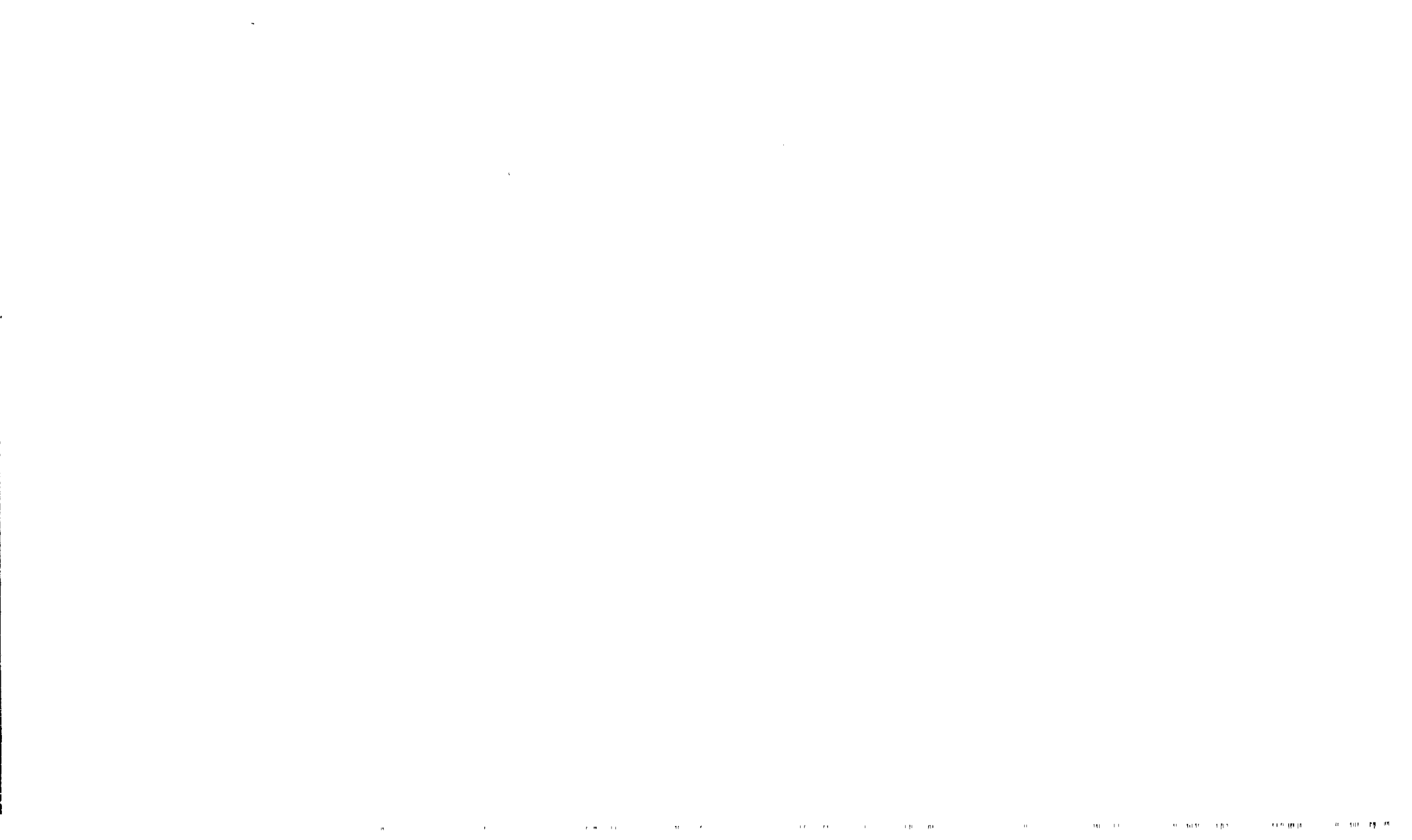

